\title{
Klasifikasi Bibit Sapi Peranakan Ongole Menggunakan Metode Pengolahan Citra
}

\author{
Leylin Fatqiyah*1, Agus Harjoko ${ }^{2}$ \\ ${ }^{1}$ Program Studi S1 Elektronika Instrumentasi, FMIPA, UGM Yogyakarta \\ ${ }^{2}$ Jurusan Ilmu Komputer dan Elektronika, FMIPA UGM, Yogyakarta \\ e-mail: *1 leylin_fatqiyah@mail.ugm.ac.id,, aharjoko@ugm.ac.id
}

\begin{abstract}
Abstrak
Sapi Peranakan Ongole adalah sapi terbanyak di Indonesia. Sapi ini juga banyak dikonsumsi oleh masyarakat Indonesia. Sapi-sapi ini diklasifikasikan menjadi tiga kelas berdasar ukurannya. Klasifikasi sapi selama ini masih dilakukan secara manual dengan mengukur bagian-bagian tertentu dari badan sapi satu persatu. Selain itu standar kelas yang ada saat ini masih terlalu tinggi dan tidak sesuai dengan kondisi yang ada di lapangan sehingga sebagian sapi tidak dapat masuk ke dalam kelas yang ada. Melihat pentingnya klasifikasi kelas sapi, maka perlu adanya suatu sistem yang mampu mengklasifikasikan sapi pernakan Ongole.

Sistem ini akan mengukur parameter persyaratan kuantitatif sapi dari citra sapi. Sistem akan mengklasifikasikan bibit sapi peranakan Ongole sesuai standar yang telah ditetapkan menggunakan pengolahan citra. Implementasi sistem menggunakan software Matlab. Sistem akan mengklasifikasikan bibit sapi peranakan Ongole ke dalam 4 kelas, yakni kelas I, kelas II, kelas III, dan luar kelas III. Dari hasil pengujian didapatkan bahwa sistem ini mampu mengukur panjang badan, lingkar dada, dan tinggi pundak dengan tingkat akurasi masingmasing 90,77\%, 93,30\%, dan 93,13\%. Sistem mampu mengklasifikasikan kelas sapi peranakan Ongole dengan tingkat akurasi sebesar $86,67 \%$
\end{abstract}

Kata kunci-Pengolahan citra, sapi peranakan ongole, klasifikasi

\begin{abstract}
Ongole crossbreed cattle has the largest population in Indonesia. These cattle ari classified into three classes. However, the classification process is carried out manually by measuring cattle's parameters. Moreover the current standard is too high and inappropriate for the existing conditions such that some cattles could not meet the classification criteria.. For this reason, it is necessary to make a system that is able to classify Ongole Crossbreed cattle.

This proposed system measures quantitative parameters from the image of a cattle. Then the system classifies the cattle based on the measured parameters. This system will classify cattles into four classes, namely class I, class II, class III, and class IV for Lany cattle smaller than class III. Based on the experiment, the system is able to measure the body lenght, the chest circumference, and the height with accuracies of 90,77\%, 93,30\% and 93,13\% respectively. This system is able to classify the class of Ongole Crossbreed cattle with an accuracy of $86,67 \%$
\end{abstract}

Keywords - Image processing, matlab, Ongole Crossbreed cattle, classification 


\section{PENDAHULUAN}

Capi Peranakan Ongole adalah salah satu sapi potong terbanyak yang diternakkan dan dikonsumsi di Indonesia. Sapi Peranakan Ongole atau yang lebih dikenal dengan sapi PO merupakan sapi terbanyak di Indonesia. Sapi PO merupakan hasil persilangan antara sapi jawa dengan sapi Sumba Ongole. Saat ini kebutuhan sapi potong lebih tinggi daripada ternak yang dihasilkan. Oleh karena itu diperlukan adanya pengembangan peternakan sapi potong.

Dalam industri peternakan, klasifikasi atau grading sapi sangatlah penting. Dari proses klasifikasi sapi maka sapi dapat digolongkan berdasarkan kelasnya. Penentuan kelas ini sangat berpengaruh pada kualitas dan kuantitas daging dari sapi-sapi tersebut. Untuk menghasilkan sapi potong yang berkualitas, maka diperlukan bibit yang berkualitas pula. Setelah mendapatkan bibit yang berkualitas, kemudian dilakukan proses penggemukan dan atau pembibitan sapi. Proses penggemukan sapi bertujuan agar sapi tersebut memiliki jumlah daging yang banyak saat dipotong nanti. Sedangkan proses pembibitan bertujuan untuk mendapatkan kualitas sapi yang baik untuk dikembang-biakkan kembali. Standarisasi Nasional telah menetapkan standar untuk klasifikasi bibit sapi Peranakan Ongole [1]. Sapi yang diteliti pada penelitian ini dibatasi pada sapi betina usia $\geq 24$ bulan. Dan klasifikasi yang diteliti hanya pada persyaratan kuantitatif saja.

Sampai saat ini penentuan kelas bibit sapi masih dilakukan dengan cara manual, yakni dengan mengukurnya satu per satu menggunakan tali atau alat ukur lainnya. Hal ini tentu saja membutuhkan proses yang sangat lama, mengingat dalam satu peternakan tidak hanya memelihara beberapa ekor sapi tapi sampai jumlah ratusan ekor.

Pengolahan citra adalah sebuah pemrosesan citra untuk mendapatkan kualitas citra dengan hasil yang lebih baik. Penelitian tentang pengolahan citra dan klasifikasi ini telah dilakukan oleh banyak orang. Usman dkk [2] melakukan penelitian untuk menentukan sistem sortasi dan pemutuan buah jeruk. Penelitian ini dilakukan pada buah Jeruk Pontianak. Perbandingan yang dilakukan juga antara berat buah dengan luas citra. Dari penelitian ini didapatkan bahwa jeruk Pontianak yang digolongkan sebagai mutu A memiliki luas area lebih besar dari 37906 piksel, untuk mutu B 37906 - 31208 piksel, mutu C 31208 - 24510, mutu D 24510 - 17812 piksel, dan mutu E kurang dari 17812 piksel.

Perwiranto [3] melakukan penelitian tentang klasifikasi mutu tomat menggunakan metode pengolahan citra digital dan jaringan saraf tiruan Dalam penelitiannya, buah tomat ditimbang secara manual kemudian dibandingkan dengan luas citra buah untuk mendapatkan persamaan berat tomat. Hasil pengujian sistem ini menunjukkan tingkat keberhasilan $88 \%$.

Wiharja [4] membuat sistem yang mampu mengklasifikasikan mutu pisang. Dalam penelitiannya, ia membuat program yang dapat mengukur panjang pisang. Kertas warna hitam berbentuk persegi panjang digunakan sebagai kalibrator agar dapat mengkalibrasi ukuran dalam pixel ke dalam sentimer. Tingkat akurasi dari pengujiannya sebesar $92,78 \%$.

\section{METODE PENELITIAN}

\subsection{Analisis dan Perancangan}

Rancangan ini berupa rancangan software pengolahan citra. Hal ini dapat dilihat pada Gambar 1. Pada proses pertama bagian atas garis putus-putus adalah rancangan untuk pembangunan sistem. Sedangkan pada proses kedua bagian bawah garis putus-putus merupakan adalah aplikasi sistem dari proses pertama sebagai sistem klasifikasi bibit sapi PO. Data yang digunakan adalah 15 ekor sapi yang diambil secara acak.

Pengukuran dilakukan dengan alat ukur tinggi dan panjang badan sapi serta pita ukur secara manual. Masing-masing dari lingkar dada, tinggi pundak, dan panjang badan diukur dan hasilnya dicatat sebagai penentu kelas sapi. Pengukuran ini nantinya akan dijadikan sebagai data perbandingan ukuran gambar dalam pixel dan ukuran sapi sebenarnya dalam centimeter $(\mathrm{cm})$. Sehingga didapatkan perbandingan $\mathrm{cm} /$ pixel. Pengambilan gambar dilakukan dengan jarak 3 meter dari objek.

IJEIS Vol. 6, No. 2, October 2016 : 199 - 210 


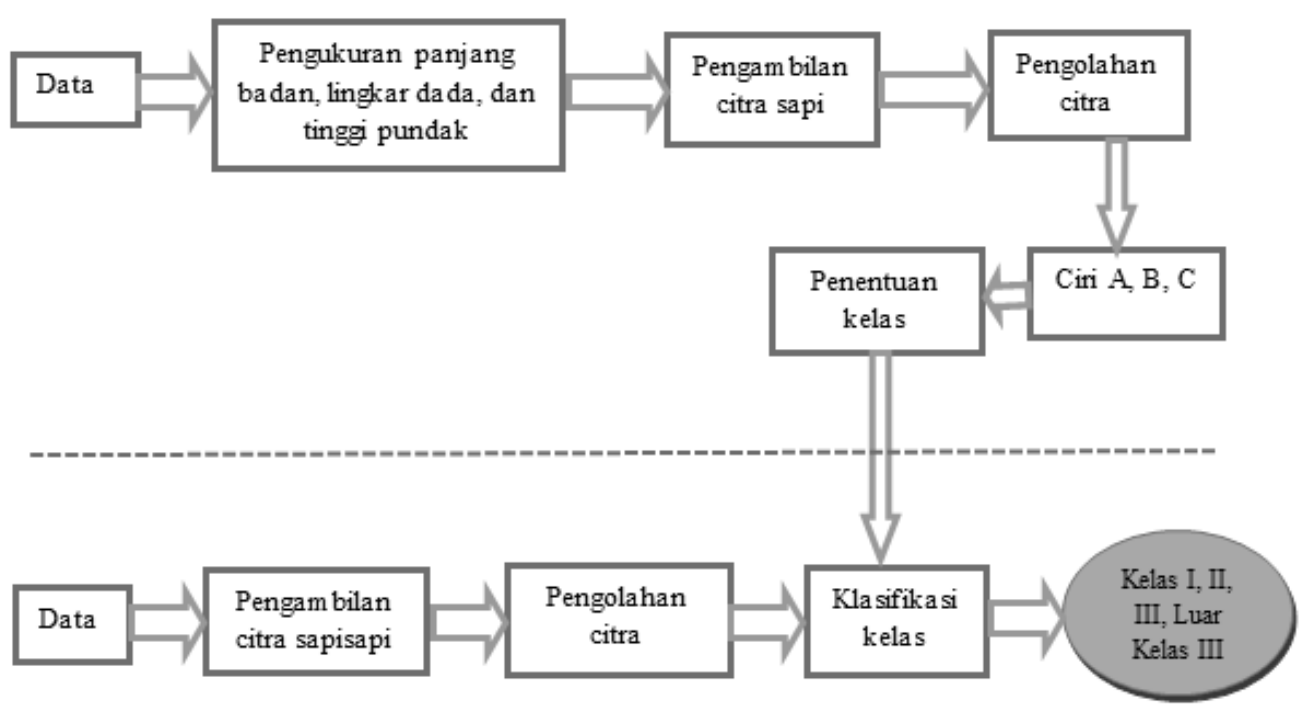

Gambar 1 Blok diagram rancangan sistem secara keseluruhan

Gambar 2 adalah diagram alir untuk kerja sistem secara keseluruhan. Program utama pengolah citra dimulai dengan membaca citra yang telah diambil sebelumnya menggunakan kamera digital. Citra yang dihasilkan oleh kamera berupa citra warna RGB berukuran 4608x3456 pixel. Citra ini dikonversi menjadi ukuran 1152x864 pixel agar program pengolah citra tidak terlalu berat dan terlalu lama dalam memproses citra. Selanjutnya pada citra akan dilakukan proses pengolahan citra untuk menghasilkan berbagai informasi dari citra yang nantinya akan digunakan pada proses klasifikasi.

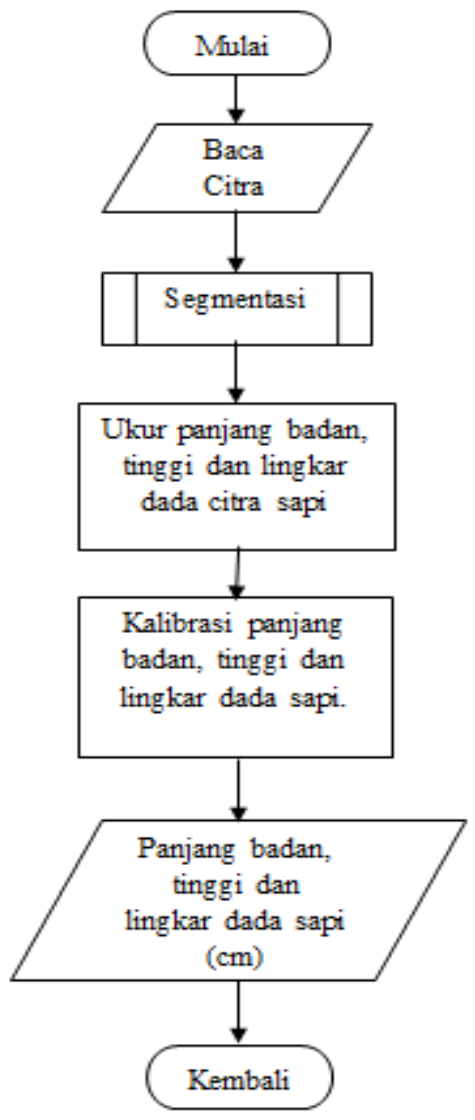

Gambar 2 Diagram alir secara keseluruhan 


\subsubsection{Perancangan Program Pengolahan Citra}

Proses pengolahan citra yang pertama dilakukan adalah proses segmentasi citra. Segmentasi pada program pengolah citra ini bertujuan untuk memisahkan objek dengan background. Segmentasi biasa dilakukan sebagai langkah awal untuk melaksanakan klasifikasi objek [5]. Rancangan program segmentasi pada sistem ini akan menggunakan metode grow cut. Tahap pertama pada proses segmentasi adalah menentukan objek (foreground) citra. Hal ini dilakukan dengan menarik garis-garis batas yang menjadi objek citra. Garis-garis batas objek ditarik mengelilingi objek. Proses selanjutnya adalah menentukan background citra. Proses penentuannya sama dengan penentuan objek citra. Pada penentuan background citra, garis-garis batas ditarik sedikit diatas garis objek yang telah dibuat. Setelah objek dan background ditentukan, selanjutnya program akan memisahkan antara objek dengan background citra dan menampilkan hasil segmentasinya. Rancangan program pengolahan citra ditunjukkan pada Gambar 3.

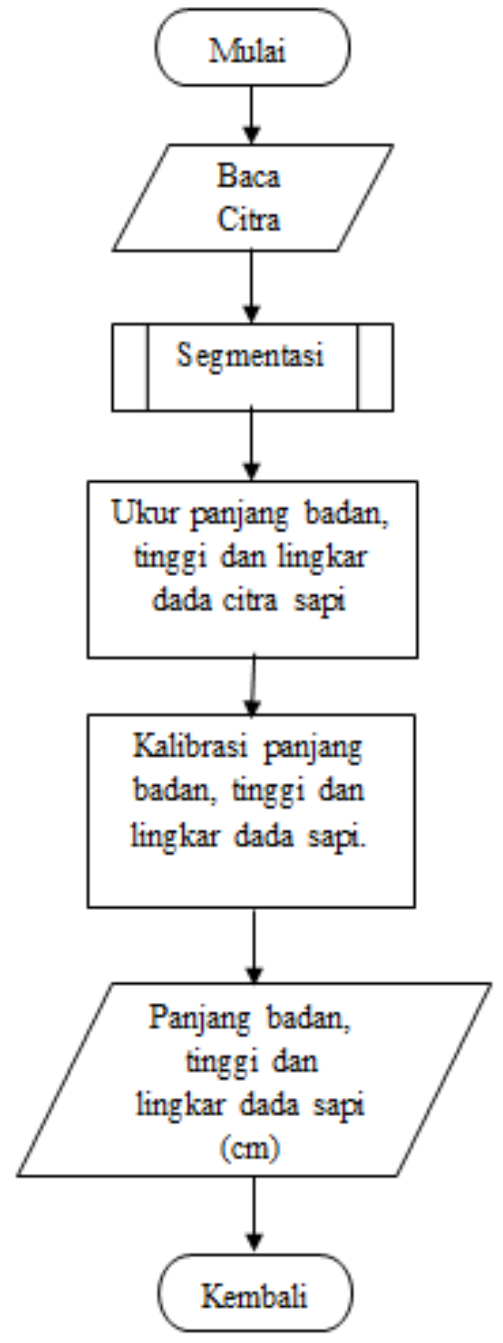

Gambar 3 Rancangan program pengolahan citra

Selanjutnya akan dilakukan pengukuran pada citra hasil segmentasi. Pengukuran dilakukan manual menggunakan fungsi imdistline pada matlab [6]. Yang akan diukur adalah panjang badan, lingkar dada dan tinggi dari citra sapi. Dari pengukuran ini akan didapatkan ketiga ciri tersebut dalam pixel. Ketiga ciri ini kemudian akan dikalibrasikan. Program pengolah citra harus mampu mengetahui ukuran sapi dari citranya. Maka dari itu diperlukan suatu 
persamaan untuk menunjukkan hubungan antara ukuran asli dengan ciri citra. Sehingga bisa diketahui setiap pixel itu mewakili berapa $\mathrm{cm}$ dari ukuran sebenarnya.

Untuk lingkar dada sebelum diukur dengan fungsi imdistline, sebelumnya diambil sampel 5 data yang diukur dengan fungsi imellipse [7]. Hal ini dilakukan karena imdistline hanya bisa mengukur garis, tidak bisa digunakan untuk mengukur lingkar dari gambar. Imellipse digunakan untuk mendapatkan pendekatan keliling dari lingkar dada citra sapi. Keliling elips ke 5 data tersebut kemudian dibandingkan dengan diameter vertikal-nya masing-masing. Dari ke 5 data tersebut kemudian diambil rata-rata perbandingan diameter dengan keliling elips.

Selanjutnya ukuran ini akan dikalibrasikan ke dalam centimeter $(\mathrm{cm})$. kalibrasi didapatkan dengan mengalikan ukuran ciri citra (pixel) dengan nilai kalibrasi. Sedangkan nilai kalibrasi didapatkan dari rata-rata hasil perbandingan ukuran asli $(\mathrm{cm})$ dengan ukuran dari citra (pixel). Khusus untuk lingkar dada, nilai kalibrasinya masih harus dikalikan lagi dengan ratarata perbandingan keliling dengan diameter vertikal dari ke 5 data yang telah dibuat sebelumnya.

\subsubsection{Perancangan Klasifikasi}

Berdasarkan SNI 7356:2008 mengenai Bibit sapi Peranakan Ongole (PO), persyaratan kuantitatif yang dijadikan acuan seleksi meliputi lingkar dada, tinggi pundak, dan panjang badan. Pada SNI ini, sapi diklasifikasikan ke dalam kelas I, II, dan III. Pada penelitian ini, sapi diklasifikasikan ke dalam kelas I, II, III dan luar kelas III. Luar kelas III adalah tambahan untuk sapi yang ukurannya di bawah kelas III. Tabel 1 menunjukkan parameter-parameter spesifikasi yang digunakan untuk proses klasifikasi.

Tabel 1 Parameter Syarat Kuantitatif

\begin{tabular}{|c|c|l|c|c|c|c|}
\hline No & $\begin{array}{c}\text { Umur } \\
\text { (bulan) }\end{array}$ & Parameter & $\begin{array}{c}\text { Kelas I } \\
(\mathrm{cm})\end{array}$ & $\begin{array}{c}\text { Kelas II } \\
(\mathrm{cm})\end{array}$ & $\begin{array}{c}\text { Kelas III } \\
(\mathrm{cm})\end{array}$ & $\begin{array}{c}\text { Luar Kelas } \\
\text { III }(\mathrm{cm})\end{array}$ \\
\hline 1 & \multirow{3}{*}{$\geq 24$} & Lingkar dada & $\geq 153$ & $139-152$ & $134-138$ & $\leq 137$ \\
\cline { 3 - 7 } & Tinggi pundak & $\geq 126$ & $121-125$ & $119-120$ & $\leq 118$ \\
\cline { 3 - 7 } & & Panjang badan & $\geq 135$ & $127-134$ & $125-126$ & $\leq 124$ \\
\hline
\end{tabular}

Pada kenyataannya, tidak semua sapi yang memiliki lingkar dada pada kelas I juga memiliki panjang badan dan tinggi pundak pada kelas I. Maka dari itu dibutuhkan sistem penentuan klasifikasi kelas yang bisa digunakan untuk kondisi yang ada. Langkah pertama pada penentuan klasifikasi ini adalah dengan memberi angka pada ukuran masing-masing parameter.. Jika ukuran sesuai dengan kelas I, maka diberi nilai 1. Jika sesuai dengan ukuran kelas II, diberi nilai 2. Kemudian jika sesuai degan ukuran kelas III, diberi nilai 3. Dan jika lebih kecil dari ukuran kelas III maka masuk ke dalam luar kelas III dan diberi nilai 4.

Penentuan klasifikasi kelas sapi dibuat dengan menjumlahkan jumlah nilai dari ketiga parameter. Sapi kelas I adalah sapi dengan jumlah parameter 3-4. Sapi kelas II adalah sapi dengan jumlah parameter 5-6. Sapi kelas III adalah sapi dengan jumlah parameter 7-10. Sapi luar Kelas III adalah sapi dengan jumlah parameter 11-12. Tabel 2 adalah tabel penentuan kelas sapi. Rancangan sistem pada program klasifikasi ditunjukkan pada Gambar 4.

Tabel 2 Klasifikasi kelas sapi PO betina

\begin{tabular}{|l|l|}
\hline Jumlah nilai parameter & Kelas Sapi \\
\hline $3-4$ & Kelas I \\
\hline $5-6$ & Kelas II \\
\hline $7-10$ & Kelas III \\
\hline $11-12$ & Luar Kelas III \\
\hline
\end{tabular}




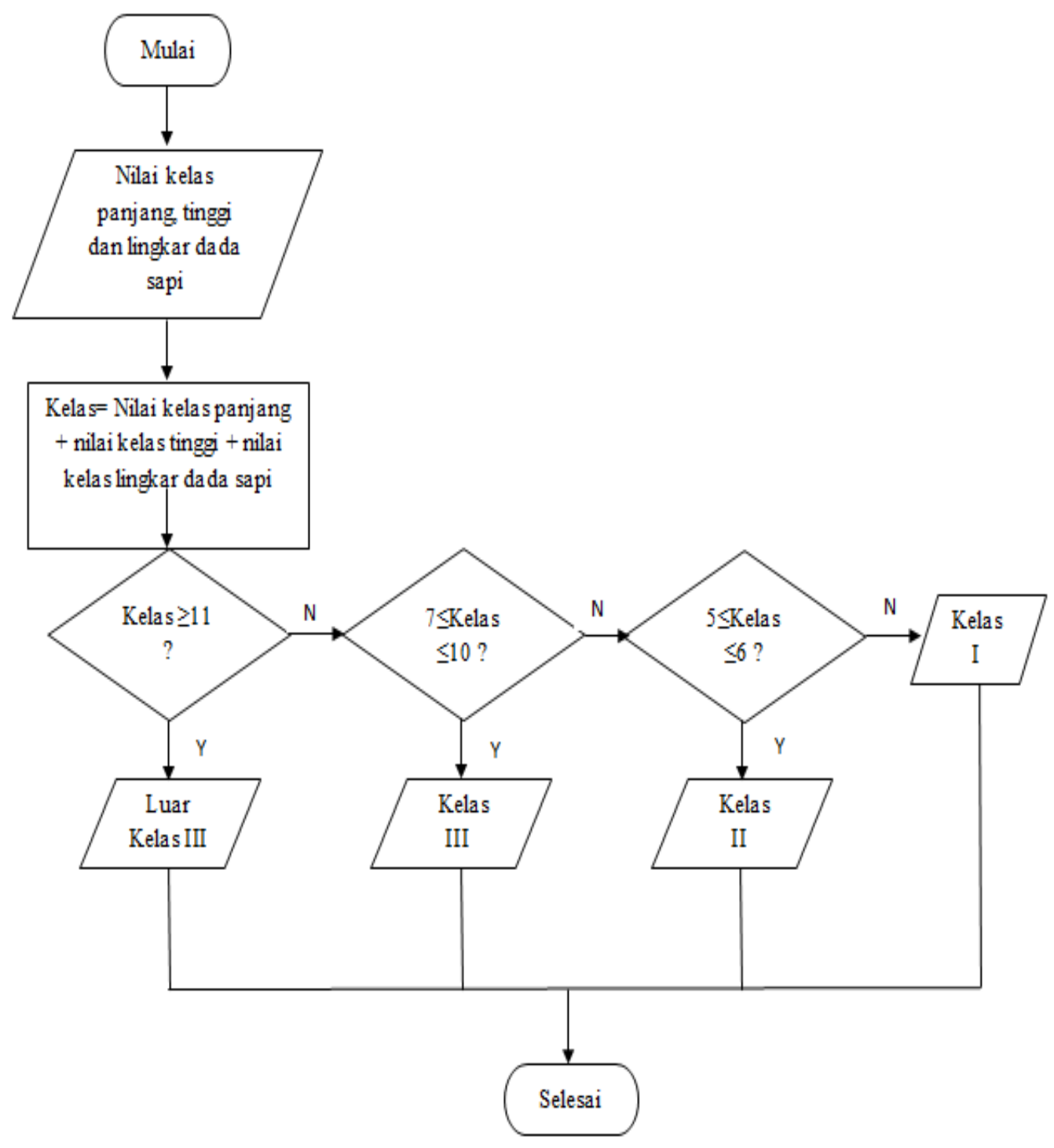

Gambar 4 Rancangan klasifikasi kelas

\subsection{Implementasi}

Citra sapi yang diambil berjumlah 15 data. Citra diambil dengan jarak 3 meter dari objek. Citra yang telah diambil menggunakan kamera digital disimpan di PC untuk kemudian diolah oleh program. Proses pengolahan berupa segmentasi, pengukuran ciri, kalibrasi dan klasifikasi.

Proses pengolahan citra ini diimplementasikan dengan program Matlab 2013a. Gambar 5 menunjukkan tampilan GUI (graphical User Interface) pada program Matlab.

GUI merupakan tampilan grafis yang memudahkan user berinteraksi [8]. Pada GUI ini terdapat 4 tombol dan 4 toolbar utama. Toolbar ${ }^{3}$ berfungsi untuk membuka citra sapi dalam yang disimpan dalam satu folder. Setelah dibuka, daftar citra akan ditampilkan dalam 'Daftar File Citra'. Klik dua kali pada nama file citra untuk menampilkan citra pada panel 1 dan panel 2. Citra yang ditampilkan dalam bentuk RGB. Citra pada panel 1 adalah citra yang akan diproses dan citra pada panel 2 adalah citra awal/asli. Toolbar zoom-in dan zoom-out berfungsi untuk memperbesar dan memperkecil bagian tertentu dari citra yang diinginkan. Hal ini bermanfaat saat proses segmentasi, agar user lebih teliti saat melakukan segmentasi. Toolbar 
pan berfungsi untuk menggeser area tertentu pada citra. Tombol 'SEGMENTASI' berfungsi untuk memanggil program segmentasi. Tombol 'Simpan' berfungsi untuk menyimpan citra hasil segmentasi. Citra hasil segmentasi akan disimpan dalam folder 'Save Result'. Tombol '+' berfungsi untuk mengukur ciri citra hasil segmentasi. Dan tombol 'HITUNG' berfungsi untuk kalibrasi dan klasifikasi kelas sapi. Hasil dari kalibrasi masing-masing akan ditampilkan pada hasil pengukuran. Dan hasil klasifikasi kelas akan ditampilkan di bawah hasil kalibrasi.

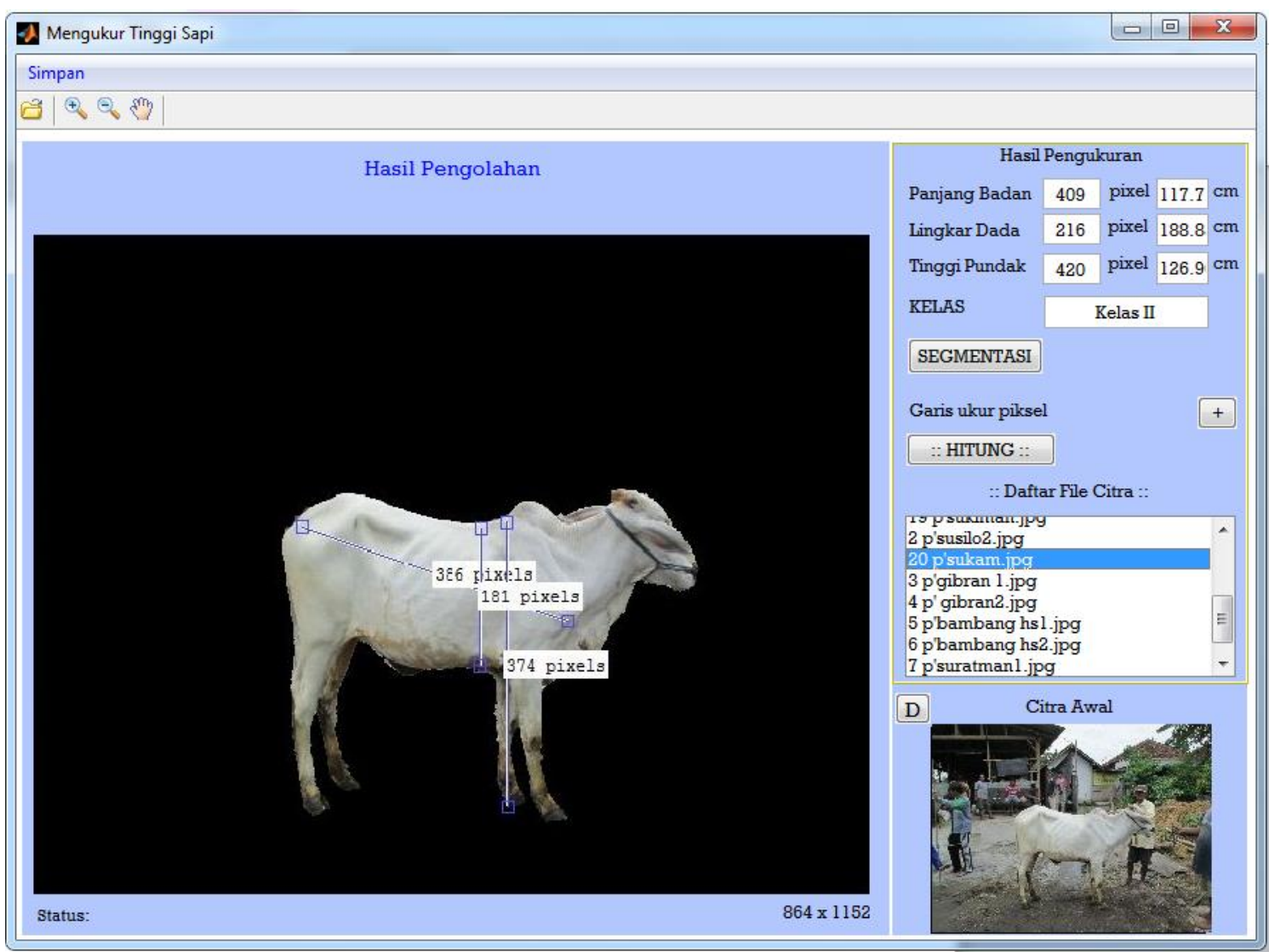

Gambar 5 Tampilan GUI sistem klasifikasi sapi peranakan Ongole

\section{HASIL DAN PEMBAHASAN}

\subsection{Pengujian Kalibrasi}

Pada bagian ini dilakukan pengujian terhadap kalibrasi. Pengujian akan dilakukan pada masing-masing panjang badan, lingkar dada dan tinggi pundak. Pengujian ini dilakukan untuk mengetahui seberapa baik kalibrasi digunakan. Nilai kalibrasi didapatkan dengan mengambil rata-rata perbandingan ukuran sebenarnya $(\mathrm{cm})$ dengan ukuran pada citra (pixel) dari data yang diambil. Nilai kalibrasi dari panjang badan dan tinggi pundak adalah 0,29. Angka ini sekaligus menandakan bahwa setiap pixel pada citra mewakili $0,29 \mathrm{~cm}$ pada ukuran sebenarnya. Nilai kalibrasi pada lingkar dada adal 1,89 x 0,46 . Angka 1,89 adalah rata-rata perbandingan keliling dengan diameter vertikal dada sapi. Dan angka 0,46 adalah rata-rata perbandingan lingkar dada $(\mathrm{cm})$ dengan keliling dada sapi (pixel). 
Keberhasilan pengujian akan menggunakan indikator berupa akurasi. Akurasi ini merupakan nilai yang meunjukkan tingkat keberhasilan sistem dalam meng-konversikan ukuran sapi dari citra. Perhitungan akurasi kalibrasi ini ditunjukkan pada persamaan (1).

$$
\text { akurasi }=100 \%-\left|\frac{\text { (pengukuran gebenarnya-pengukuran dengan program) }}{\text { penguhuran sebenarnya }} x 100 \%\right|
$$

Akurasi hasil pengujian program kalibrasi pengukuran panjang badan ditunjukkan pada Tabel 3. Sedangkan Tabel 4 adalah akurasi hasil pengujian program kalibrasi pengukuran lingkar dada. Dan Tabel 5 adalah akurasi hasil pengujian program kalibrasi pengukuran tinggi pundak.

Pada pengukuran tinggi pundak, akurasi paling tinggi terdapat pada data ke-14 dengan nilai 97,37\%. Selisih hasil pengukuran sebenarnya dengan program sebesar 2,7 cm. Dan akurasi terendah pada data ke-15 dengan nilai 78,97\%. Selisih pengukuran sebenarnya dengan program sebesar 20,6 cm.

Pada pengukuran lingkar dada, akurasi tertinggi pada data ke-14 dengan nilai 98,29\%. Selisih pengukuran pengukuran sebenarnya dengan program sebesar $2,5 \mathrm{~cm}$. dan akurasi terendah pada data ke-2 dengan nilai akurasi 87,00\%. Selisih pengukuran sebenarnya dengan program sebesar $19,5 \mathrm{~cm}$.

Tabel 3 Akurasi hasil pengujian program kalibrasi pengukuran panjang badan

\begin{tabular}{|l|l|l|l|}
\hline \multirow{2}{*}{ Data } & \multicolumn{2}{|l|}{ Pengukuran Panjang Badan } & \\
\cline { 2 - 3 } & $\begin{array}{l}\text { Sebenarnya } \\
(\mathrm{cm})\end{array}$ & $\begin{array}{l}\text { Program } \\
(\mathrm{cm})\end{array}$ & $\begin{array}{l}\text { Akurasi } \\
\%\end{array}$ \\
\hline 1 & 110 & 114.2 & 96.18 \\
\hline 2 & 106 & 116.5 & 90.09 \\
\hline 3 & 110 & 124.4 & 86.90 \\
\hline 4 & 110 & 122.3 & 88.81 \\
\hline 5 & 113 & 100.6 & 89.02 \\
\hline 6 & 100 & 97.1 & 97.10 \\
\hline 7 & 112 & 104.9 & 93.66 \\
\hline 8 & 112 & 97.73 & 87.25 \\
\hline 9 & 121 & 102.6 & 84.79 \\
\hline 10 & 101 & 107.5 & 93.56 \\
\hline 11 & 101 & 112.2 & 88.91 \\
\hline 12 & 101 & 109 & 92.07 \\
\hline 13 & 97 & 93.96 & 96.86 \\
\hline 14 & 103 & 100.3 & 97.37 \\
\hline 15 & 98 & 118.6 & 78.97 \\
\hline Rata-Rata & & 90.77 \\
\hline
\end{tabular}


Tabel 4 Akurasi hasil pengujian program kalibrasi pengukuran lingkar dada

\begin{tabular}{|c|c|c|c|}
\hline \multirow[b]{2}{*}{ Data } & \multicolumn{2}{|c|}{ Pengukuran Lingkar Dada } & \multirow[b]{2}{*}{$\begin{array}{l}\text { Akurasi } \\
\%\end{array}$} \\
\hline & $\begin{array}{l}\text { Sebenarnya } \\
(\mathrm{cm})\end{array}$ & $\begin{array}{l}\text { Program } \\
(\mathrm{cm})\end{array}$ & \\
\hline 1 & 150 & 167.7 & 88.20 \\
\hline 2 & 150 & 169.5 & 87.00 \\
\hline 3 & 165 & 183.4 & 88.84 \\
\hline 4 & 153 & 161.7 & 94.31 \\
\hline 5 & 164 & 157.3 & 95.91 \\
\hline 6 & 155 & 145.1 & 93.61 \\
\hline 7 & 160 & 149.5 & 93.43 \\
\hline 8 & 161 & 151.2 & 93.91 \\
\hline 9 & 170 & 160.8 & 94.58 \\
\hline 10 & 161 & 153.8 & 95.52 \\
\hline 11 & 171 & 166.0 & 97.07 \\
\hline 12 & 163 & 157.3 & 96.50 \\
\hline 13 & 156 & 141.7 & 90.83 \\
\hline 14 & 147 & 149.5 & 98.29 \\
\hline 15 & 173 & 187.7 & 91.50 \\
\hline \multicolumn{3}{|c|}{ Rata-Rata } & 93.30 \\
\hline
\end{tabular}

Tabel 5 Akurasi hasil pengujian program kalibrasi pengukuran tinggi pundak

\begin{tabular}{|c|c|c|c|}
\hline \multirow{2}{*}{ Data } & \multicolumn{2}{|c|}{$\begin{array}{l}\text { Pengukuran Tinggi } \\
\text { Pundak }\end{array}$} & \multirow{2}{*}{$\begin{array}{l}\text { Akurasi } \\
\%\end{array}$} \\
\hline & $\begin{array}{l}\text { Sebenarnya } \\
(\mathrm{cm})\end{array}$ & $\begin{array}{l}\text { Program } \\
(\mathrm{cm})\end{array}$ & \\
\hline 1 & 121 & 122.6 & 98.67 \\
\hline 2 & 120.1 & 116.8 & 97.25 \\
\hline 3 & 121 & 137.7 & 86.19 \\
\hline 4 & 115 & 118.6 & 96.86 \\
\hline 5 & 122 & 103.5 & 84.83 \\
\hline 6 & 119 & 111 & 93.27 \\
\hline 7 & 122 & 111 & 90.98 \\
\hline 8 & 121 & 101.2 & 83.63 \\
\hline 9 & 126 & 107.3 & 85.15 \\
\hline 10 & 113 & 105.5 & 93.36 \\
\hline 11 & 108 & 114.5 & 93.98 \\
\hline 12 & 125 & 118.3 & 94.64 \\
\hline 13 & 108 & 108.7 & 99.35 \\
\hline 14 & 116 & 115.4 & 99.48 \\
\hline 15 & 121 & 121.8 & 99.33 \\
\hline \multicolumn{3}{|c|}{ Rata-Rata } & 93.13 \\
\hline
\end{tabular}


Pada pengukuran tinggi pundak, akurasi tertinggi pada data ke-14 dengan nilai 99,48\%. Selisih pengukuran pengukuran sebenarnya dengan program sebesar 0,6 cm. Dan akurasi terendah pada data ke-8 dengan nilai akurasi $83,63 \%$. Selisih pengukuran sebenarnya dengan program sebesar $19,8 \mathrm{~cm}$

Dari pengujian kalibrasi diketahui bahwa rata-rata akurasi program kalibrasi pada pengukuran panjang badan sebesar 90,77\%, pada pengukuran lingkar dada sebesar 93,30\% dan pada pengukuran tinggi pundak sebesar 93,13\%. Angka ini menunjukkan bahwa program cukup baik dalam mengukur parameter kuantitatif sapi.

\subsection{Pengujian Klasifikasi Kelas}

Pada bagian ini akan dilakukan pengujian terhadap program klasifikasi kelas sapi. Sama halnya dengan pengujian program kalibrasi pengukuran, indikator yang digunakan pada pengujian ini juga dalam nilai akurasi. Nilai akurasi program klasifikasi didapatkan dengan membandingkan jumlah sapi yang terklasifikasi dengan benar dengan jumlah total sapi yang diuji. Perhitungan akurasi pada pengujian ini ditunjukkan pada persamaan (2)

$$
\text { akurasi }=\frac{j u m l a h \text { sapi yang terklasifikasi dengan benar }}{\text { jumlah total sapi }} \times 100 \%
$$

Tabel 6 adalah hasil pengukuran dan klasifikasi sapi. Sedangkan hasil pengujian program klasifikasi kelas ditunjukkan pada tabel. Dari Tabel 6 diketahui bahwa akurasi program klasifikasi kelas sapi sebesar 86,67\%. Angka ini menunjukkan bahwa program cukup baik dalam mengklasifikasikan kelas sapi.

Tabel 6 Hasil pengujian program klasifikasi sapi

\begin{tabular}{|c|l|c|c|c|c|c|}
\hline \multicolumn{2}{|c|}{} & \multicolumn{4}{|c|}{ Hasil Deteksi } & \multirow{2}{*}{$\begin{array}{c}\text { Akurasi } \\
\%\end{array}$} \\
\cline { 3 - 7 } \multicolumn{2}{|c|}{} & Kelas I & $\begin{array}{c}\text { Kelas } \\
\text { II }\end{array}$ & $\begin{array}{c}\text { Kelas } \\
\text { III }\end{array}$ & $\begin{array}{c}\text { Luar Kelas } \\
\text { III }\end{array}$ & \\
\hline \multirow{3}{*}{$\begin{array}{c}\text { Mutu } \\
\text { Sebenarnya }\end{array}$} & Kelas I & 0 & 0 & 0 & 0 & \\
\cline { 2 - 6 } & Kelas II & 0 & 0 & 1 & 0 & \multirow{3}{*}{86.67} \\
\cline { 2 - 6 } & Kelas III & 0 & 1 & 13 & 0 & \\
\cline { 2 - 6 } & Luar Kelas III & 0 & 0 & 0 & 0 & \\
\hline
\end{tabular}

Dapat dilihat pada Tabel 6, dari 15 sapi yang diuji terdapat 1 ekor sapi kelas II dan 14 ekor sapi kelas III. Dan hasil klasifikasi dapat dilihat pada Tabel 6 bahwa sapi kelas II terdeteksi sebagai sapi kelas III. Sapi kelas III berhasil terdeteksi sebanyak 13 sapi, sedangkan sisanya terdeteksi sebagai kelas II sebanyak 1 sapi.

Pada data ke-3 Tabel 6 panjang badan sapi pada pengukuran sebenarnya sebesar $110 \mathrm{~cm}$ dan masuk pada luar kelas III. Akan tetapi pada pengukuran dengan program terukur sebesar 124,4 dan masuk pada kelas III. Selain itu, tinggi sapi pada pengukuran sebenarnya $121 \mathrm{~cm}$ dan masuk pada kelas II terukur dengan program sebesar $137,7 \mathrm{~cm}$ yang masuk pada kelas I. Perbedaan hasil pengukuran ini akan mempengaruhi jumlah nilai parameter sehingga hasil klasifikasi sapi berbeda dari yang seharusnya sapi kelas III terklasifikasi sebagai sapi kelas II.

Hal inilah yang dapat menyebabkan adanya sapi yang tidak terklasifikasi dengan benar. Selain itu, jumlah data yang digunakan juga hanya 15 data dengan penyebaran kelas yang tidak 
sama dimungkinkan dapat mempengaruhi hasil klasifikasi. Penambahan jumlah data dimungkinkan dapat memperbaiki nilai akurasi.

\section{KESIMPULAN}

Dari penelitian yang telah dilakukan dapat diambil kesimpulan sebagai berikut:

- Sistem dapat mengkalibrasi dengan tingkat akurasi $90,77 \%$ pada pengukuran panjang badan, $90,30 \%$ pada pengukuran lingkar dada dan $93,13 \%$ pada pengukuran tinggi pundak.

- Metode yang diusulkan dapat mengklasifikasikan kelas sapi dengan tingkat keberhasilan sebesar $86,67 \%$.

\section{SARAN}

Pada penelitian ini masih terdapat beberapa hal yang perlu disempurnakan. Berikut saran-saran yang penulis sampaikan untuk penelitian yang serupa.

- Sistem dapat diperbaiki dan dikembangkan dengan mengatur ketinggian kamera saat pengambilan gambar sehingga tepat di tengah objek.

- Sistem dapat dikembangkan dengan membuat pengukuran parameter-parameter sapi secara otomatis.

\section{DAFTAR PUSTAKA}

[1] Badan Standarisasi Nasional, 2008, Standar Nasional Indonesia Bibit Sapi Peranakan Ongole, http://disnakkeswan.lampungprov.go.id/sni/sni_7356-2008_bibit_sapi_po.pdf diakses pada tanggal 15 September 2012.

[2] Ahmad, U., Tjahjohutomo, R. dan Mardison, S., 2008, Pengembangan Mesin Sortasi Dan Pemutuan Buah Jeruk Dengan Sensor Kamera CCD, Prosiding Seminar Nasional Teknik Pertanian, Yogyakarta.

[3] Perwiranto, H., 2011, Sistem Klasifikasi Mutu Buah Tomat Menggunakan Pengolahan Citra Digital dan Jaringan Saraf Tiruan, Skripsi, FMIPA, UGM, Yogyakarta.

[4] Wiharja, Y. P., Harjoko, A, 2014, Pemrosesan Citra Digital untuk Klasifikasi Mutu Pisang Menggunakan Jaringan Saraf Tiruan, IJEIS, Vol.4, on.1, 2014

[5] Kadir, A dan Susanto, A, 2013, Teori dan Aplikasi Pengolahan Citra Digital, Penerbit Andi, Yogyakarta.

[6] Matlab Analyst, Imdistline, http://mathworks.com/help/images/ref/imdistline.html, diakses April 2014. 
[7] Matlab Analyst, Imellipse, http://www.mathworks.com/help/images/ref/imellipse.html? searchHighlight=imelipse, diakses Oktober 2014.

[8] Paulus, E dan Nataliani, Y, 2007, GUI Matlab, Penerbit Andi, Yogyakarta. 